\title{
Cell attachment on diamond-like carbon coating
}

\author{
D J LI* and $\mathbf{H} \mathbf{Q} \mathbf{G U}^{\dagger}$ \\ Department of Physics, Tianjin Normal University, Tianjin 300074, P.R. China \\ ${ }^{\dagger}$ Institute of Urologic Surgery, Tianjin 300211, P.R. China
}

MS received 21 July 2001; revised 22 October 2001

\begin{abstract}
Preliminary results of diamond-like carbon (DLC) coating with its novel properties with no toxicity have caused a strong interest of commercial manufacturers of surgical implants. DLC coatings were prepared on polymethylmethacrylate (PMMA) at room temperature using ion beam assisted deposition (IBAD). It could be shown by X-ray photoelectron spectroscopy, Auger electron spectroscopy, and Raman spectroscopy that DLC coating prepared by $800 \mathrm{eV} \mathrm{CH^{n+ }}$ beam bombardment possessed a higher fraction of $s p^{3}$ bonds in the structure of mixed $s p^{3}+s p^{2}$ bonding, resulting in a higher hydrophobicity. The results of the cell attachment tests indicated that DLC coatings exhibited low macrophage attachment and provided desirable surface for the normal cellular growth and morphology of the fibroblasts. At the same time, the number of both neutral granulocytes and platelets adhering to DLC coatings decreased significantly. These findings showed that DLC was a better coating with desirable tissue and blood compatibility.
\end{abstract}

Keywords. Diamond-like carbon; ion beam assisted deposition; cell attachment.

\section{Introduction}

Polymer is used mainly in fabrication of various implants and medical devices in the medical materials industry due to its desirable properties like light weight, moldability, and ability to form intricate shapes. Besides, the chemical composition containing only carbon, hydrogen, oxygen, and nitrogen makes it possess better biocompatibility. In recent years, however, it has become increasingly apparent that a large number of implants made of polymers suffers from long-term failure in the body, which makes them difficult to be permanent or semi-permanent components in the body. The major causes of failure are directly or indirectly related to their low wear resistance and corrosion resistance, resulting in severe reaction in response to the wear particles and corrosion products. These clinical problems lead to infection, thinning of the implants, blood coagulation, and cellular damage (Wolter 1990; Courtney et al 1993, 1994; Ikada 1994). Therefore, an inert, wear-reducing and corrosion-reducing coating on polymers is of interest to the biomedical industry.

Diamond-like carbon (DLC) coating can adhere well to a variety of metallic and non-metallic substrates. It is conceivable that the unique combination of high chemical inertness and wear resistance can make DLC a potential candidate for coating on biopolymers (Franks et al 1988; Thomson et al 1991; Matthews and Eskildsen 1993; Cui and Luo 1999). Although some studies have demonstrated that DLC has no toxicity toward certain cells ( $\mathrm{Lu}$ et al

*Author for correspondence
1993; McColl et al 1993; Matthews et al 1994; Parker et al 1994), a large number of tests on cell attachment are needed to obtain significant indications of biocompatibility of DLC coatings.

Ion beam assisted deposition (IBAD) is currently one of the applied techniques for preparing hard coatings close to room temperature. It presents an opportunity to prepare DLC on the surface of various biopolymers as well as their devices. In our previous papers ( $\mathrm{Li}$ et al 1999a, 2000), we used this technique to synthesize DLC coatings on the medical polymer. This work, as a logical extension to previous works, was performed to synthesize DLC coating on polymethylmethacrylate (PMMA) using IBAD with different $\mathrm{CH}^{n+}$ beam bombarding energies, and to investigate the effects of the bombarding energy on the chemical states and several sensitive cell attachment of the coatings by means of extensive spectroscopic experiments and cultured cell in vitro. We chose PMMA as a substrate because it is the first choice polymer for use in fabrication of the ophthalmic introcular lens and likely to have applications ranging from semi-permanent to permanent implants.

\section{Experimental}

PMMA samples with $6 \mathrm{~mm}$ dia. and $2 \mathrm{~mm}$ thickness were used as the substrates for cell attachment and chemical state analysis. They were cleaned sequentially in an ultrasonic bath of ethyl alcohol solution for 10 min prior to deposition. 
DLC coatings were prepared in an IBAD system, mainly consisting of three broad-beam ion sources of Kaufman type, one rotatable water-cooled sample holder, and one rotatable water-cooled target holder. The base pressure of the vacuum chamber was about $1 \times 10^{-3} \mathrm{~Pa}$. Before deposition, the substrates were cleaned by $\mathrm{Ar}^{+}$ (1 keV, $15 \mathrm{~mA}$ ) bombardment for $2 \mathrm{~min}$. A pure graphite target was sputtered by $\mathrm{Ar}^{+}(3 \mathrm{keV}, 40 \mathrm{~mA})$ to deposit the carbon films, and resulting films were simultaneously bombarded by $\mathrm{CH}^{n+}$ beam $(10 \mathrm{~mA})$ at energies of 150 and $800 \mathrm{eV}$ from another ion source. The film thickness was about $60 \mathrm{~nm}$ for the cell attachment and chemical state tests.

Four types of sensitive cells were inoculated on the surface of DLC coatings and control PMMA to assess the cell attachment.

The macrophage is a suitable cell for in vitro tissue compatibility as it plays a major role in inflammation and the response to foreign bodies. In this experiment, the macrophage suspension with a concentration of $1 \times 10^{6}$ cells/ml was obtained according to the method described in our previous paper ( $\mathrm{Li}$ et al 1999b). The fibroblast is another often used cell in tissue compatibility tests. Our fibroblasts, provided by Institute of Hematology, Chinese Academy of Medical Science, were 3T3 cells of freshly killed mice. The 3T3 cells were cultured in Dulbeco's Minimum Essential Medium (DMEM) containing 10\% FBS. After the centrifugalization at $1000 \mathrm{rev} / \mathrm{min}$ for $6 \mathrm{~min}$, the fibroblasts were grown in DMEM containing $8 \%$ foetal bovine serum (FBS) to obtain the fibroblast suspension in which the cell concentration was $1 \times 10^{6}$ cells $/ \mathrm{ml}$.

The neutral granulocyte and the platelet belong to blood cells. Their attachment on the surface of biomaterials is related to the blood compatibility of the materials. The neutral granulocyte and the platelet suspensions were obtained from normal human blood. Their preparation details were described elsewhere ( $\mathrm{Li}$ et al 1999b).

The samples with and without DLC coatings were rinsed in phosphate buffered saline (PBS), and then reconditioned by immersion in physiological saline (pH 7.4) for several hours. The suspensions $(20 \mu \mathrm{l})$ of the macrophage, fibroblast, neutral granulocyte, and platelet respectively were inoculated on the surface of these samples respectively. The incubation period was $48 \mathrm{~h}$ for the macrophage and the fibroblast attachment tests, and $2 \mathrm{~h}$ for the neutral granulocyte and platelet attachment tests. After incubation in atmosphere of $5 \% \mathrm{CO}_{2}$ in air at $37^{\circ} \mathrm{C}$, the supernatant was removed and the samples were rinsed carefully five times using PBS $(\mathrm{pH} 7 \cdot 2)$ prior to fixation. Twenty independent samples were measured for each cell attachment test. In each test, the number of the neutral granulocytes and platelets adhering to each sample was quantitatively determined by counting the cells adhering to the central region $\left(0.04 \mathrm{~mm}^{2}\right)$. On the other hand, the growth and morphology of the macrophages and fibroblasts on the surface of the samples were observed by means of an optical microscope equipped with phase contrast objectives.

X-ray photoelectron spectroscopy (XPS), Auger electron spectroscopy (AES), and Raman spectroscopy were applied to analyse the chemical states of the coatings on PMMA.

\section{Results and discussion}

\subsection{Cell attachment analysis}

Figure 1 shows the number of the neutral granulocytes adhering to the samples with and without DLC coatings at different $\mathrm{CH}^{n+}$ beam bombarding energies with other conditions being identical. Each value in this figure represents the mean $\pm \mathrm{SD}$ for 20 independent samples. Our statistical data indicate that there is a significant difference in the number of adhered neutral granulocytes between the control and DLC coated samples. It is apparent that DLC coatings prepared at two different bombarding energies exhibit relatively low neutral granulocyte attachment. The number of cells adhering to the control sample is $3.2 \times 10^{3}$ cells $/ \mathrm{mm}^{2}$; its value came down to $2.5 \times 10^{3}$ cells $/ \mathrm{mm}^{2}$ after the cells were grown on DLC coating prepared at $150 \mathrm{eV} \mathrm{CH}^{n+}$ beam bombarding energy. When the bombarding energy is up to $800 \mathrm{eV}$, the coating exhibits lower number of neutral granulocytes $\left(2 \cdot 1 \times 10^{3}\right.$ cells $\left./ \mathrm{mm}^{2}\right)$. The above result indicates that $\mathrm{CH}^{n+}$ beam bombarding energy can be helpful for synthesizing DLC films with desirable chemical states, which leads to a low neutral granulocyte attachment.

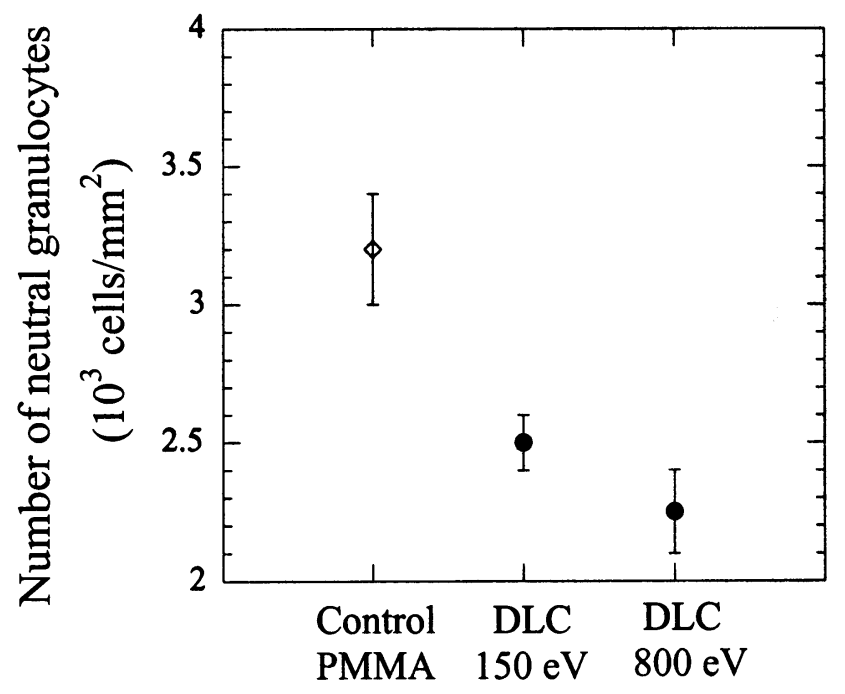

Figure 1. The number of neutral granulocytes adhering to the control PMMA and DLC coatings prepared at different $\mathrm{CH}^{n+}$ beam bombarding energies. 
A similar result from the platelet attachment test is given in figure 2. Compared with the control sample, DLC coatings show a lower platelet attachment. $800 \mathrm{eV} \mathrm{CH}^{n+}$ beam bombardment during the film synthesis can result in a more obvious decrease in the number of the platelets adhering to the surface of DLC coating. Because platelet and neutral granulocyte are blood cells, a high attachment of these cells can accelerate blood coagulation. So it is desired that their attachment to the surface of biomaterial is low. The above result indicates good blood compatibility of DLC coatings.

Figure 3 shows the relation between the number of macrophages adhering to the surfaces of DLC coatings and $\mathrm{CH}^{n+}$ beam bombarding energy. Dramatic differences between the control PMMA and DLC-coated samples are apparent. Among three surfaces, DLC coating prepared at $800 \mathrm{eV}$ exhibits lowest cell attachment. This result implies that $\mathrm{CH}^{n+}$ beam bombarding energy can control the structural characterization of DLC coatings that is related to the cell attachment. The optical microscopic pictures could prove this result. It is clear from figure 4 that the number of macrophages adhering to DLC prepared at $800 \mathrm{eV}$ is lower than that adhering to control PMMA. The macrophage is a kind of immune cell that attacks bacteria and foreign microorganisms in the body. The surfaces with good tissue compatibility should not exhibit much macrophage. This result shows that the macrophages do not display strong response to DLC coatings.

The morphology and growth of 3T3 fibroblasts on the surface of DLC coating prepared at $800 \mathrm{eV}$ are observed using optical microscope. It can be seen that the $3 \mathrm{~T} 3$ cells growing on DLC coating have adhered well to the surface and exhibit normal cellular growth (figure 5a). There is no evidence of extensive cell death. From the single-layer cellular morphology in figure $5 \mathrm{~b}$ it can be observed that the 3T3 fibroblasts show normal cellular morphology. The cells stretch out to form polygons, and the intersections of the cellular filopodia can be observed. Those results clearly indicate that DLC coating is not toxic to the fibroblasts. Matthews et al (1994) and Parker et al (1994) have also determined 3T3 cell viability in Millicell-PCF membrane inserts with and without DLC coatings by trypan blue dye exclusion. Their results indicated that the growth rate of cells exposed to the DLC coating was similar to that for cells grown on uncoated inserts, indicating that the DLC coating had no adverse effect on normal cellular activity. This clearly showed that the DLC was not toxic to the growing $3 \mathrm{~T} 3$ cells, which is in agreement with our results.

\subsection{Chemical state analysis}

The above results have shown that the $\mathrm{CH}^{n+}$ beam bombarding energy can cause dramatic changes in the cell attachment on DLC coatings. A factor contributing to the observed effects seems to be related to the structural characterization change of the coatings. To check this change and explain the reason why $\mathrm{CH}^{n+}$ beam bombarding energy can control the cell attachment, XPS, AES and Raman analyses are conducted to study differences in the chemical states between the DLC coatings prepared at different $\mathrm{CH}^{n+}$ beam bombarding energy. Figures 6-8 present characteristic XPS, Raman, and AES signals for the samples used for the cell attachment tests.

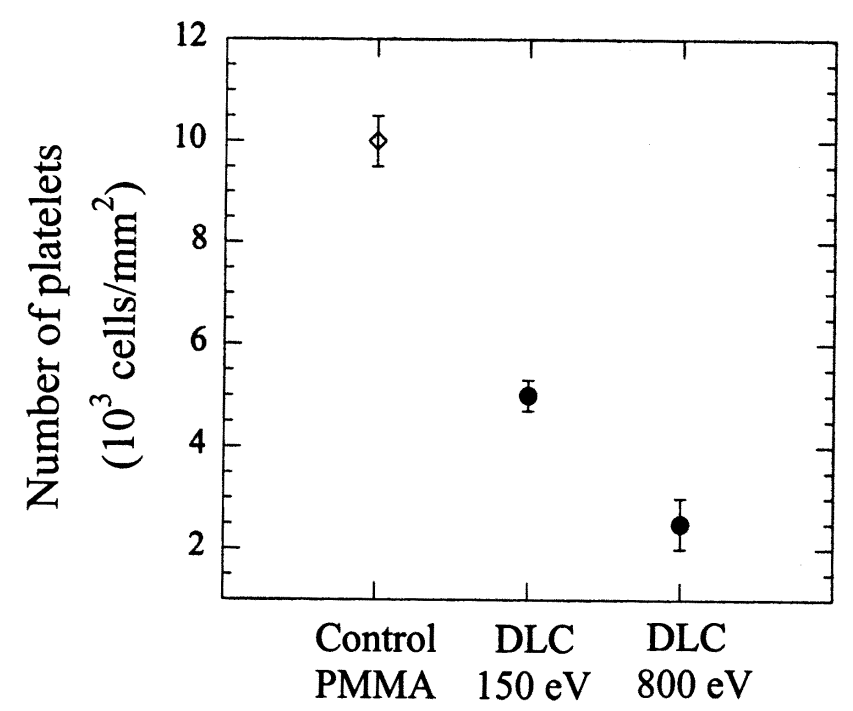

Figure 2. The number of platelets adhering to the control PMMA and DLC coatings prepared at different $\mathrm{CH}^{n+}$ beam bombarding energies.

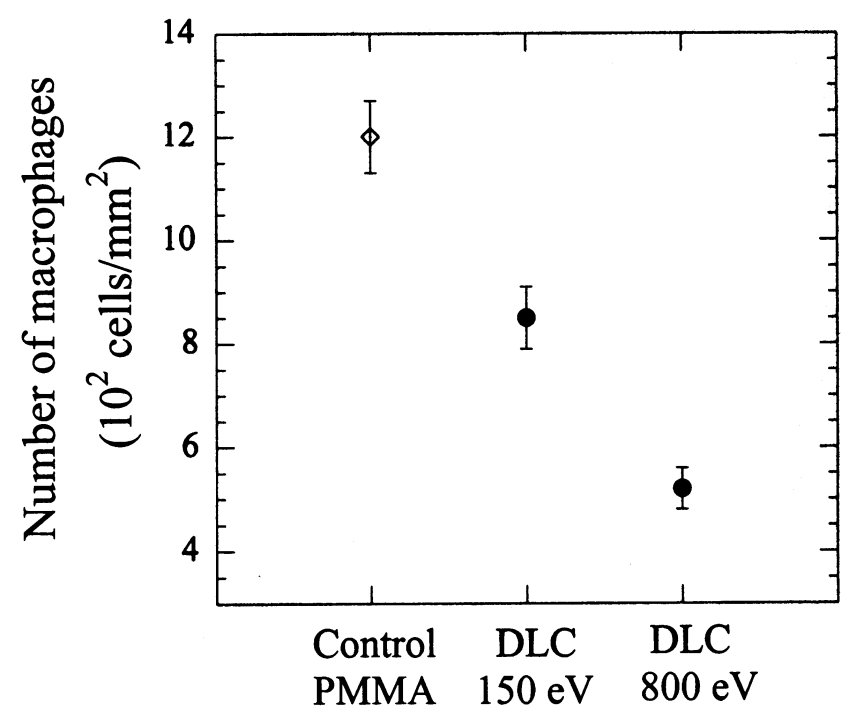

Figure 3. The number of macrophages adhering to the control PMMA and DLC coatings prepared at different $\mathrm{CH}^{n+}$ beam bombarding energies. 
A VG ESCALAB 5 multi-techniques electron spectrometer was employed to carry out XPS measurements. In this analysis, $\mathrm{Al} \mathrm{K}_{\alpha} \mathrm{X}$-ray $(10 \mathrm{kV}, 20 \mathrm{~mA})$ was used to induce electron ejection from the coatings on PMMA, and the photoelectrons were collected with a $50 \mathrm{eV}$ pass energy, a $0.05 \mathrm{eV}$ step size, and a $100 \mathrm{~s}$ scan time. Figure 6 shows the valence-band XPS signals of DLC coatings prepared at 150 and $800 \mathrm{eV}$. For comparison, the valenceband spectra of diamond and graphite are shown in this figure. There are three distinct regions in the valenceband spectrum of diamond. A peak between 16 and $21 \mathrm{eV}$ binding energy in region 1 arises from $s$-like bonds, a peak between 10 and $15 \mathrm{eV}$ in region 2 represents a strong mixture of $s$ and $p$ characters, and a peak between 3 and $10 \mathrm{eV}$ in region 3 corresponds to $p$ bonds. It is clear from figure 6 that the valence-band spectra of two coatings are different from pure graphite. For the coating prepared at $150 \mathrm{eV}$, it is composed of $s p^{3}+s p^{2}$ bonding indicated by the peak at the binding energy of $10.2 \mathrm{eV}$, which means that the coating prepared at this bombarding energy possesses $s-p$ mixed bonding in its structure, i.e. it is diamond-like. When bombarding energy increased to $800 \mathrm{eV}$, the peak shape and peak position in region 2 are more closer to that of diamond, indicating the coating prepared at $800 \mathrm{eV}$ possesses more stronger $s-p$ mixed bonding and higher fraction of $s p^{3}$ bonds in the structure of mixed $s p^{3}+s p^{2}$ bonding, i.e. it tends to be more diamond-like.

Stronger evidence of the above phenomenon can also be observed by Raman analysis. A Double Slit Raman
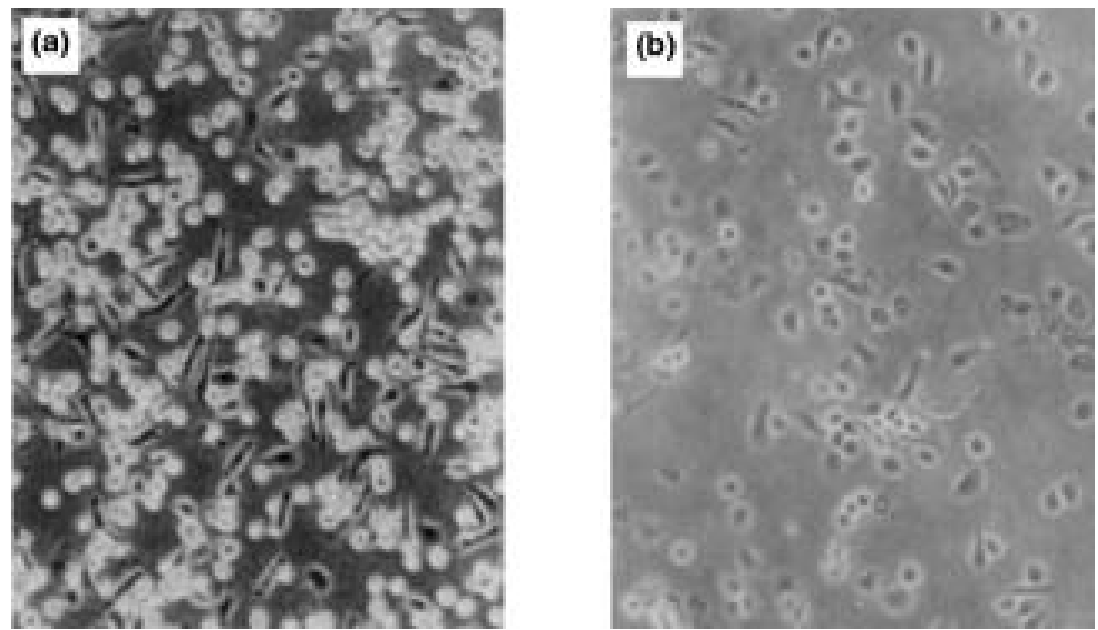

Figure 4. Optical microscopic picture showing the macrophages adhering to the control PMMA (a) and DLC coating prepared at $800 \mathrm{eV}$ (b) (magnification $\times 400$ ).
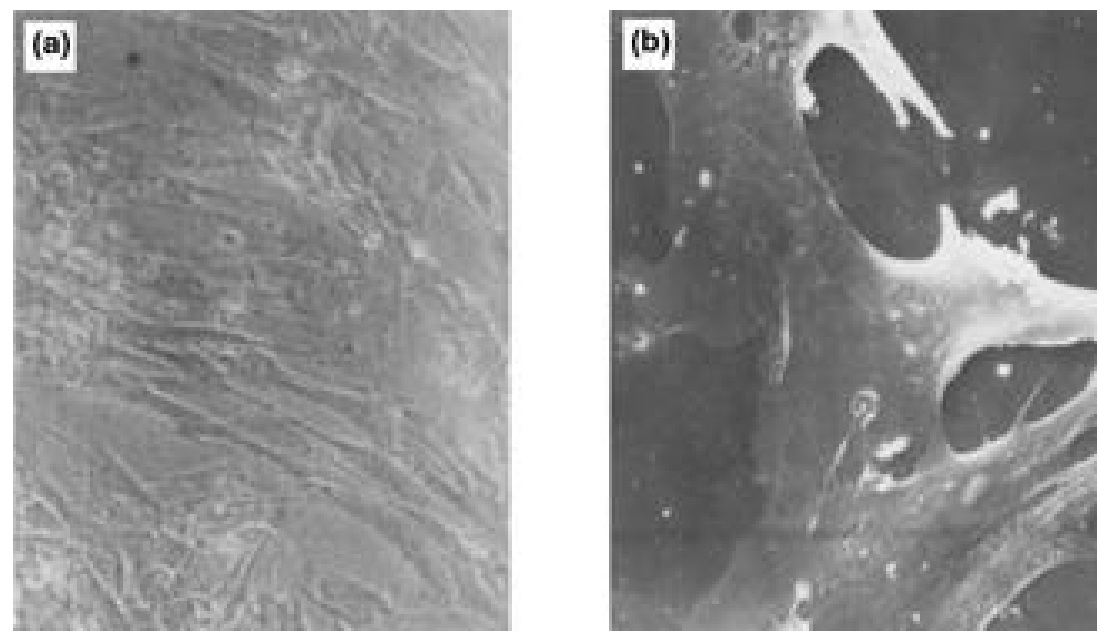

Figure 5. Optical microscopic picture showing the fibroblasts adhering to DLC coating prepared at $800 \mathrm{eV}$. (a) cellular growth (magnification $\times 200$ ) and (b) single-layer cellular morphology (magnification $\times 1000)$. 
System was used to perform Raman analysis of DLC coatings. In this experiment, a $100 \mathrm{~mW} \mathrm{Ar}^{+}$ion laser with a wavelength of $534.5 \mathrm{~nm}$ was used. The measurement conditions were as follows: slit size was $600 \mu \mathrm{m}$, scan step size was $2 \mathrm{~cm}^{-1}$, and scan time $0 \cdot 2 \mathrm{~s}$. Figure 7 shows Raman spectra of DLC films prepared by 150 and $800 \mathrm{eV}$ $\mathrm{CH}^{n+}$ beam bombardment. As seen in figure 7, two spectra have a broad peak at about $1530 \mathrm{~cm}^{-1}$, corresponding to that the carbon films are principally amorphous carbon. The second broad peak around $1360 \mathrm{~cm}^{-1}$, indicating the presence of disordered graphite induced by $s p^{3}$ carbon atoms, is also included in two Raman spectra of DLC films. Although two coatings consist of amorphous carbon and disordered graphite, DLC film prepared at $800 \mathrm{eV}$ is to be more diamond-like. This result indicates that $\mathrm{CN}_{x}$ coating prepared at $800 \mathrm{eV}$ possesses more stronger $s-p$ mixed bonding. In other words, the $800 \mathrm{eV} \mathrm{CH}^{n+}$ beam bombarding energy can induce more fraction of $s p^{3}$ bonds in its structure of mixed $s p^{2}+s p^{3}$ bonding. This result is in excellent agreement with that of the above XPS analysis.

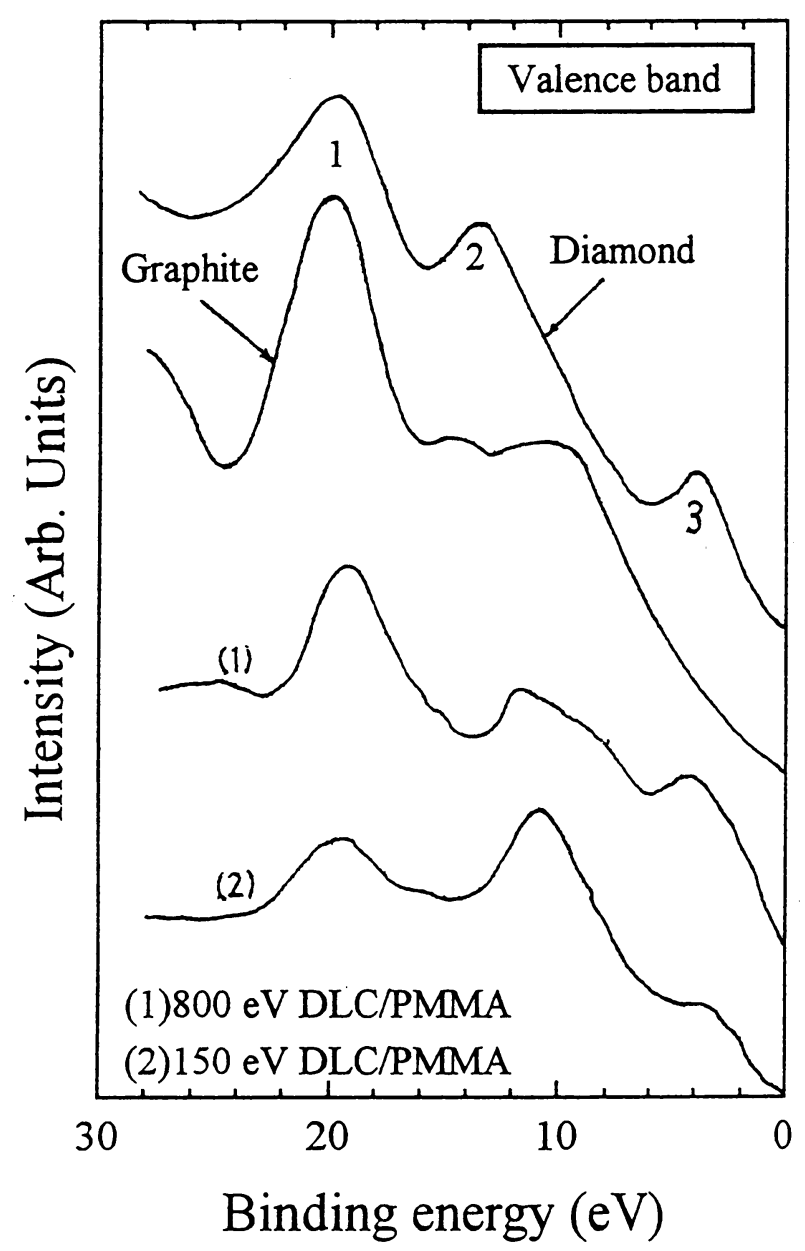

Figure 6. Valence-band XPS spectra of diamond, graphite, and the DLC coatings prepared at different $\mathrm{CH}^{n+}$ beam bombarding energies.
Figure 8 is a typical Auger spectrum of DLC coating deposited on PMMA at $800 \mathrm{eV}$. It shows the presence of mainly carbon. The existence of oxygen is due to air exposure during sample transport and is readily removed by 5 min of $3 \mathrm{KeV} \mathrm{Ar}^{+}$sputtering.

\subsection{Discussion}

In this study, the neutral granulocytes, platelets, macrophages, and fibroblasts were used to examine the cell attachment in order to obtain further significant indications of blood and tissue compatibility of DLC coatings. It is well known that high neutral granulocyte and platelet attachment produces negative effects on blood compatibility of implants. On the other hand, high macrophage attachment produces negative effects on the tissue compatibility of implants; no normally grown fibroblast is known to produce serious consequences on the longterm implantation of biomaterials. Our results indicate that the cell attachment on the surface of DLC coatings can be controlled by deposition parameters during the coating synthesis. The cell attachment changes depend upon the $\mathrm{CH}^{n+}$ beam bombarding energy. The $800 \mathrm{eV}$ $\mathrm{CH}^{n+}$ beam bombardment is better for the significant decrease in the number of neutral granulocytes, platelets, and macrophages adhering on the surface of DLC coating, which is of great value to minimize the blood coagulation and adverse interaction. The normal cellular growth

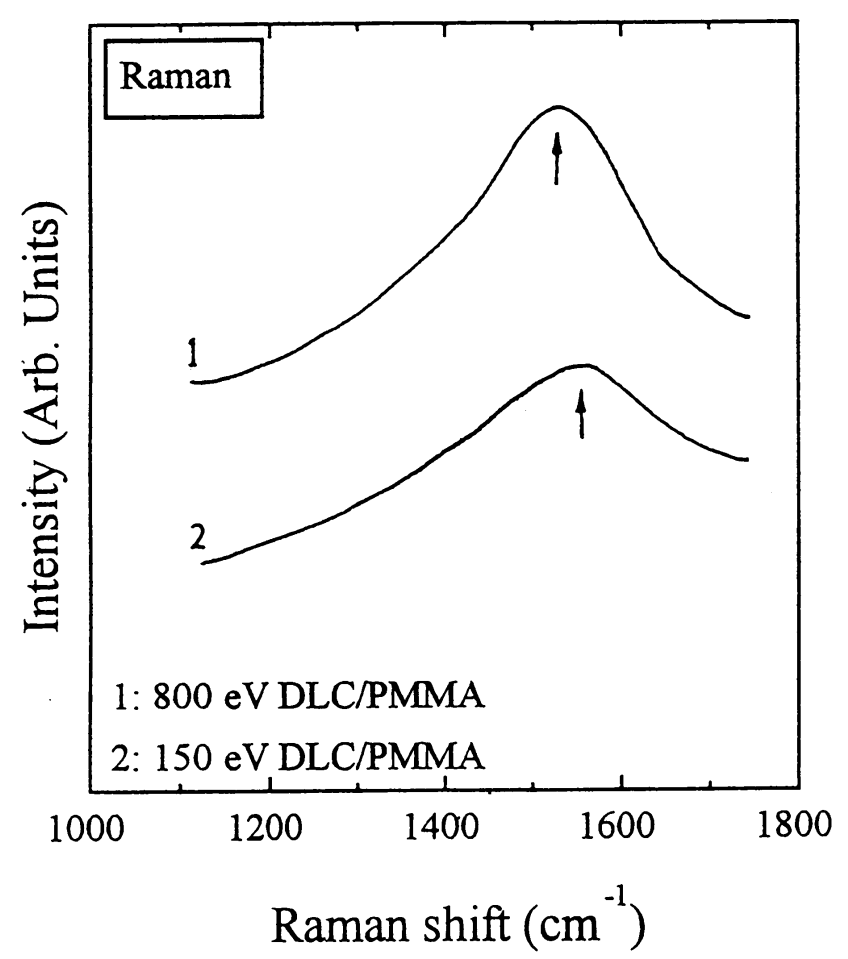

Figure 7. Raman spectra of DLC coatings prepared at different $\mathrm{CH}^{n+}$ beam bombarding energies. 


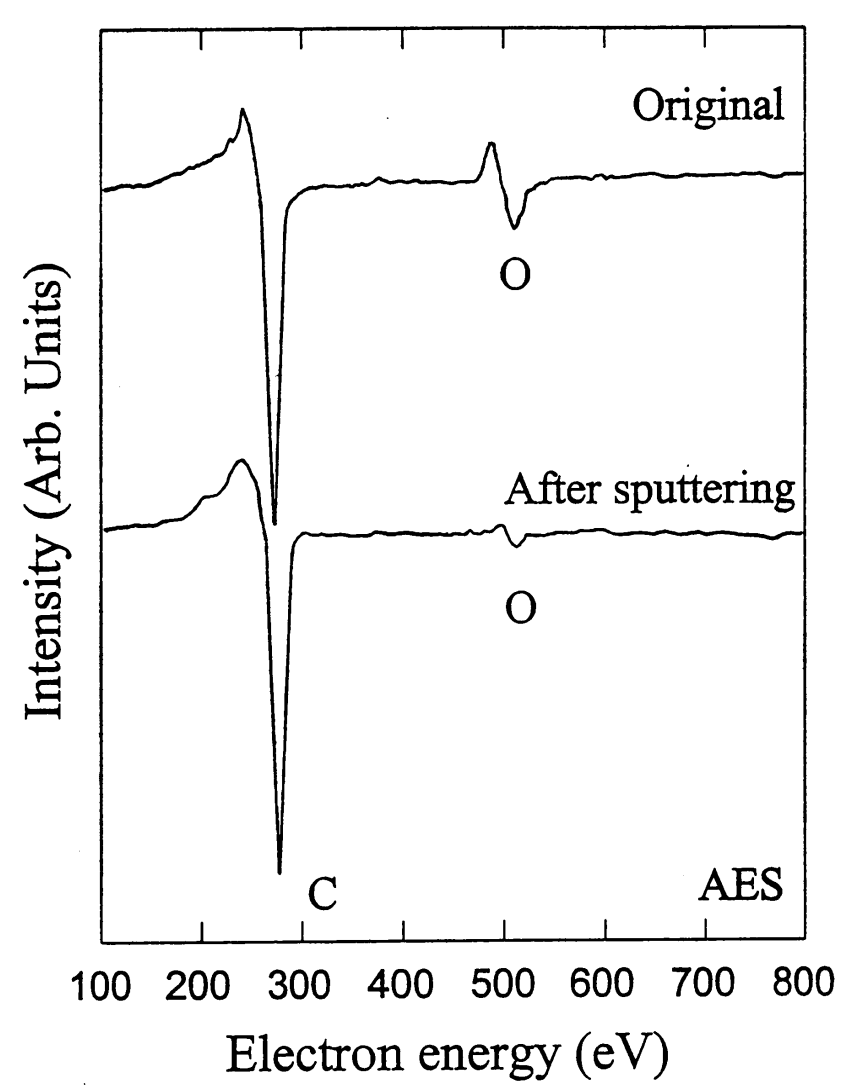

Figure 8. AES spectra of DLC coating prepared at $800 \mathrm{eV}$.

of the $3 \mathrm{~T} 3$ fibroblasts on the surface can also result in a positive effect on the clinical applications of DLC coating.

On the other hand, our results show that the $\mathrm{CH}^{n+}$ ion beam bombarding energy can also control the chemical state of DLC coatings during synthesis. Compared with the $150 \mathrm{eV}$, the $800 \mathrm{eV}$ ion beam bombardment leads to a higher fraction of $s p^{3}$ bonds in the structure of mixed $s p^{3}+s p^{2}$ bonding, which implies that the fraction of $s p^{3}$ bonds in the structure of DLC coatings is related to the cell attachment changes.

Our previous paper has indicated that some sensitive cells such as neutral granulocytes and macrophages do not try to adhere to more hydrophobic surface (Li et al 1999b). Upon this idea, we consider DLC coating with higher fraction of $s p^{3}$ bonds may exhibit higher hydrophobicity. To check the hydrophobicity of DLC coatings, the measurements of the water contact angle were performed. Figure 9 shows the contact angles of the samples with and without DLC coatings at different $\mathrm{CH}^{n+}$ beam bombarding energies. It is clear that the $800 \mathrm{eV}$ ion beam bombardment leads to a higher contact angle, i.e. higher hydrophobicity, which may be one of the reasons for inhibiting the attachment of the neutral granulocytes, platelets, and macrophages.

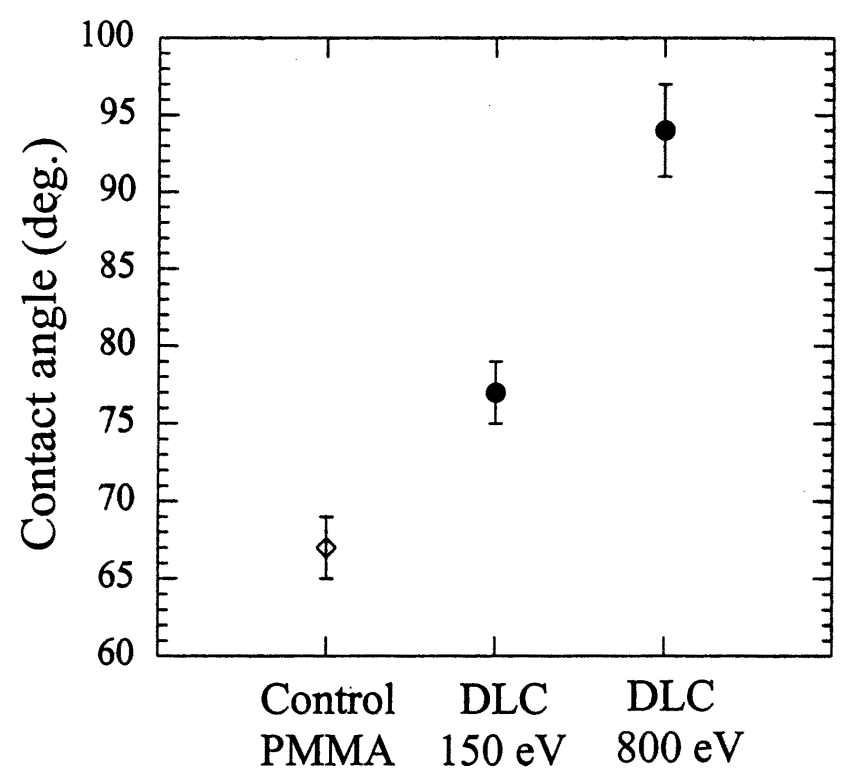

Figure 9. Contact angle of the control PMMA and DLC coatings prepared at different $\mathrm{CH}^{n+}$ beam bombarding energies.

\section{Conclusions}

In summary, we have shown that DLC coatings can be deposited on PMMA at room temperature using IBAD technique. A study of the cell attachment has been made for the coatings. The chemical state was also analysed. The cell attachment, the hydrophobicity, and the chemical state of the coatings are related to the $\mathrm{CH}^{n+}$ beam bombarding energy during synthesis. XPS, AES, and Raman analyses show that the $800 \mathrm{eV}$ ion bombarding energy results in the coating to be more diamond-like. At this bombarding energy, DLC coating with a characteristic high fraction of $s p^{3}$ bonds in the structure of mixed $s p^{3}+s p^{2}$ bonding exhibits a high hydrophobic surface, which is responsible for the cell attachment changes.

\section{Acknowledgements}

This work is supported by the National Natural Science Foundation of China under Grant No. 10075034 and the Foundation for University Key Teacher by the Ministry of Education of China.

\section{References}

Courtney J M, Sundaram S and Forbes C D 1993 Management of bleeding disorders in surgical practice (eds) C D Forbes and A Cushieri (Oxford: Blackwell Scientific)

Courtney J M, Lamba N M K, Sundaram S and Forbers C D 1994 Biomaterials 15737

Cui F Z and Luo Z S 1999 Surf. Coat. Technol. 112278 
Franks J, Ng T L and Wright A C 1988 Vacuum 38749

Ikada Y 1994 Biomaterials 15725

Li D J, Cui F Z and Gu H Q 1999a Appl. Surf. Sci. 13730

Li D J, Cui F Z and Gu H Q 1999b Biomaterials 201889

Li D J, Cui F Z, Gu H Q and Li W Z 2000 Vacuum 56205

Lu L, Jones M W and Wu R L C 1993 Biomed. Mater. Eng. 3223

Matthews A and Eskildsen S S 1993 Diamond Films 931

Matthews A, Frances L and Rushton N 1994 Clinical Mater. 171
McColl I R, Grant D M, Green S M, Wood J V, Parker T L, Parker K, Goruppa A A and Braithwaite N St J 1993 Diamond Relat. Mater. 383

Parker T L, Parker K L, McColl I R, Grant D M and Wood J V 1994 Diamond Relat. Mater. 31120

Thomson L A, Law F C, Rushton N and Franks J 1991 Biomaterials 1237

Wolter J R 1990 Biomaterials in ophthalmology (Bologna: Academic) 